\title{
Pengaruh Metode Eksperimen Menggunakan Model Problem Based Learning (PBL) Terhadap Hasil Belajar Siswa Pada Materi Larutan Elektrolit dan Non Elektrolit
}

\author{
Justitia Mifthania Bulotio ${ }^{* a}$, Ni Wayan Suriani ${ }^{a}$, Rymond J. Rumampuk ${ }^{a}$ \\ a Pendidikan Kimia, FMIPA, Universitas Negeri Manado, Minahasa, 95618, Indonesia
}

\begin{tabular}{l} 
I N F O A R T I K E L \\
\hline Diterima 21 Juli 2020 \\
Disetujui 30 Desember 2020 \\
\\
\hline Keywords: \\
Experimental Method \\
Problem Based Learning \\
Learning Outcomes \\
Electrolyte and Non Electrolyte \\
\hline Kata kunci: \\
Metode Eksperimen \\
Problem Based Learning \\
Hasil Belajar \\
Elektrolit dan Non Elektrolit \\
\hline
\end{tabular}

e-mail:

justitiabulotio23@gmail.com

\begin{abstract}
A BSTRACT
The research is limited to the problem of the effect of the experimental method using the problem-based learning model to determine whether this effect of the experimental method using the problem-based learning model on the average student learning outcomes on electrolyte non-electrolyte solution. This research is the experimental research conducted in X class of MIA MAN 1 Bitung in the academic year 2019/2020 and uses two classes, namely class X MIA 1 as an experimental class and class X MIA 2 as a control class. The results of research in the experimental class given the experimental method used the PBL model obtained an averaged value of 89,2 while for the control class that was only given the experimental method obtained an averaged value of 50,6. For testing the hypothesis obtained that $\mathrm{H}_{1}$ is accepted so it can be stated that the student average learning outcomes applied by the experimental method used the problem-based learning model are higher than those using only the experimental method
\end{abstract}

\begin{abstract}
A BSTRAK
Penelitian bertujuan mengetahui apakah terdapat pengaruh metode eksperimen menggunakan model Problem Based Learning (PBL) terhadap rata-rata hasil belajar siswa untuk materi larutan elektrolit dan non elektroli.. Penelitian ini merupakan penelitian eksperimen yang diberikan di kelas X MIA MAN 1 Bitung pada tahun ajaran ajaran 2019/2020, dan menggunakan dua kelas yaitu kelas X MIA 1 sebagai kelas eksprimen dan kelas X MIA 2 sebagai kelas kontrol. Untuk hasil penelitian di kelas eksperimen yang diberikan metode eksperimen menggunakan model Problem Based Learning (PBL) diperoleh nilai 89,2 sedangkan pada kelas kontrol yang hanya diberikan metode eksperimen memperoleh nilai ratarata 50,6. Untuk pengujian hipotesis yang diperoleh yaitu $\mathrm{H}_{1}$ diterima sehingga dapat dinyatakan bahwa rata-rata nilai siswa yang diterapkan metode eksperimen menggunakan Model PBL lebih besar dibanding dengan yang hanya menggunakan metode eksperimen saja.
\end{abstract}

\section{Pendahuluan}

Pembelajaran kimia merupakan proses pembelajaran yang menekan siswa pada pemberian proses belajar secara langsung untuk mencapai tujuan pembelajaran. Dari hasil observasi di MAN 1 Bitung, kimia merupakan pelajaran sulit bagi kebanyakan siswa karena banyaknya teori, hafalan rumus serta unsur-unsur yang harus dipelajari sehingga membuat sebagian besar siswa cenderung beranggap kimia sebagai pelajaran sulit dan abstrak karena mereka sering gagal menemukan kaitan antara konsep yang dipelajari sehari-hari serta ketidak tahuan siswa dalam praktik sehari-hari. Pada proses pembelajaran, guru juga merupakan salah satu bagian dalam pendidikan, yang berperan sebagai pembimbing dalam kegiatan pembelajaran untuk membuat siswa terlibat penuh dalam proses pembelajaran [1,2]. 
Berdasarkan pengalaman yang peneliti dapatkan saat menjadi siswa SMA dan menjadi guru pada saat mengikuti PPL, kurangnya keterlibatan siswa selain yang diuraikan diatas juga bergantung pada peran guru di dalam kelas. Kebanyakan siswa hanya diajarkan dengan metode ceramah, setelah itu diberikan tugas rumah supaya siswa lebih paham dengan materi. Namun yang menjadi permasalahan, memang ada siswa yang cepat dalam memahami materi walaupun hanya diberikan metode ceramah, tetapi ada juga sebagian siswa yang sulit atau lambat dalam mencerna atau memahami materi bila hanya diajarkan dengan matode ceramah dan langsung diberikan tugas [3]. Hal tersebut dapat mempengaruhi keterlibatan siswa pada proses mengajar dan belajar, dan berujung pada nilai siswa yang kurang pada mata pelajaran kimia[4].

Ilmu kimia merupakan suatu cabang pengetahuan alam yang dikembangkan dan diperoleh melalui ujicoba serta mempunyai peran sangat penting untuk kehidupan seharihari sehingga menjadi bagian penting dalam menunjang penguasaan ilmu dasar contohnya biologi, dan astronomi serta ilmu terapan seperti pertanian, pertambangan, perikanan, kesehatan dan teknologi. Mengingat bahwa ilmu kimia adalah ilmu yang sangat penting, maka pembelajaran kimia perlu diajarkan secara menarik untuk tujuan agar siswa bisa menguasai ilmu kimia dengan baik melalui kegiatan belajar dan mengajar yang membuat siswa terlibat langsung.

Beberapa materi di SMA khususnya di kelas $\mathrm{X}$ memerlukan metode praktikum guna untuk pembuktian prinsip, teori-, serta hukum yang telah dipelajari, karena pada dasarnya kimia merupakan subjek yang melibatkan yang bisa dilakukan dengan percobaan di laboratorium agar materi yang disampaikan lebih mudah diingat oleh siswa [5-7]. Selain itu metode praktikum dapat memberikan kesempatan pada siswa untuk membuat percobaan untuk mengalami serta membuktikan sendiri sesuatu telah dipelajari [8-10]. Larutan elektrolit dan non elektrolit adalah melupakan materi yang memerlukan praktikum. Tetapi tidak bisa dipungkiri aktivitas praktikum di sekolah kadang masih mengalami banyak kendala diantaranya alat dan bahan harganya relatif mahal, sulit dijangkau serta tidak tersedianya laboratorium.

Kendala-kendala tersebut dapat diatasi dengan menggantikan alat atau bahan dalam praktikum dengan alat atau bahan yang mudah dijangkau yaitu yang sering digunakan dalam kkeseharian. Pada wawancara dengan guru kimia yang ada di MAN 1 Bitung, guru tersebut menyatakan bahwa selama beliau mengajar belum pernah memberikan praktikum larutan elektrolit dan non elektrolit karena tidak tersedianya fasilitas laboratorium, sehingga kegiatan eksperimen di sekolah tidak dapat dijalankan. Padahal kegiatan eksperimen juga bisa dilakukan diluar laboratorium.

Berdasarkian observasi, peneliti menemukan cara untuk melakukan praktikum walaupun diluar laboratorium, dengan alat dan bahan yang terdapat pada kehidupan seharihari yang tidak berbahaya dan mudah dijangkau, seperti larutan garam, larutan cuka, dan larutan gula yang dapat dijadikan indikator dalam percobaan praktikum larutan elektrolit dan non elektrolit.

Eksperimen bertujuan untuk mengembangkan keahlian proses sains dan sikap ilmiah siswa, namun untuk lebih optimal lagi jika dipadukan dengan penunjang lainnya seperti memadukan metode eksperimen dengan model PBL. Model pembelajaran ini merupakan model yang mengharuskan siswa dalam menggunakan dan mengumpulkan informasi sebagai pemecah masalah, sehingga siswa diharapkan dapat mengembangkan keterampilan berpikir kritis dalam pemecahan masalah, menjadi siswa yang mandiri hingga dapat memberoleh peningkatan dalam hasil belajar [11,12]. Mengingat pentingnya perpaduan antara metode dan modeltersebut, peneliti melakukan penelitian terkait pengaruh metode eksperimenj menggunakan model PBL terhadap nilai siswa pada materi larutan elektrolit dan non elektrolit.

\section{Metode}

Penelitian dilakukan di MAN 1 Bitung pada bulan januari-februari tahun ajaran 2019/2020. Bentuk penelitian yaitu penelitian eksperimen dengan "posttest only control group design". 


\section{Hasil dan Pembahasan}

Penelitian ini dilakukan di MAN 1 Bitung, Provinsi Sulawesi Utara, dengan menggunakan dua kelas yaitu kelas X MIA 1 sebagai kelas eksperimen dengan siswa dan kelas X MIA 2 sebagai kelas kontrol.

\section{Hasil Uji Instrumen Penelitian}

\section{Uji Validitas}

Pengujian ini melibatkan korelasi Pearson Product Moment dari 5 soal butir soal essay setelah diuji validitas semua soal valid, sehingga kelima soal tersebut layak digunakan.

\section{Uji Reliabilitas}

Uji reliabilitasdi penelitian ini yaitu teknik belah dua dari Spearman Brown (split half), dengan diperoleh perhitungan data rhitung = 0,567 dan rtabel $=0,4$. Maka, posttest dinyatakan reliabel karena rhitung $>$ rtabel, sehingga soal posttest tersebut bias dijadikan instrumen.

\section{Hasil Uji Prasyarat}

1. Uji Normalitas

Pengujian ini digunakan untuk mengetahui apakah distribusi data normal atau tidak. Uji yang digunakan adalahuji Lilifors dengan perhitungan Microsoft excel yang memperoleh Lhitung $=0,166$ dan Ltabel $=0,173$ di kelas eksperimen dan di kelas kontrol diperoleh Lhitung $=0,154$ dan Ltabel $=0,173$ dengan kriteria uji Lhitung $<$ Ltabel, maka data berdistribusi normal.

\section{Uji Homogenitas}

Pengujian ini untuk menguji kesamaan varians dengan taraf $\alpha=0,05$. Hasil uji homogenitas di kelas kontorl dan eksoerimen diperoleh Fhitung $=1,82$ dan Ftabel $=3$,44. karena Fhitung $<$ Ftabel, maka varians kedua kelas tersebut dapat dinyatakan homogeny

\section{Deskripsi Data Penelitian}

Penelitian ini dilakakukan di MAN 1 Bitung pada kelas X MIA, dimana untuk kelas $X$ MIA 1 yaitu sebagai eksperimen dan kelas $X$ MIA 2 sebagai kelas control dengan setiapkelas berjumlah 25 siswa yang mengikuti posttest. Sebelum posttest dilaksanakan, sebelumnya soal posttest tersebut sudah diuji terlebih dahulu di kelas yang sudah pernah mendapatkan materi larutan elektrolit dan non elektrolit. Pengambilan data dari penelitian ini yaitu untuk mengetahui rata-rata hasil belajar siswa yang diterapkan metode eksperimen menggunakan model PBL. Setelah proses belajar mengajar dan kegiatan eksperimen dilakukan, dilanjutkan dengan memberikan soal posttest pada kelas eksperimen maupun kelas control.

\section{Hasil Uji Hipotesis}

Uji ini yaitu menentukan hasil posttest untuk mengetahui nilai hasil belajar siswa yang menggunakan metode eksperimen menggunakan model PBL. Hipotesis Penelitianini adalah $H_{0}: \mu_{1} \leq \mu_{2}=$ nilai hasil belajar siswa menggunakan metode eksperimen menggunakan model PBL lebih kecil atau sama dengan rata-rata hasil belajar siswa menggunakan metode eksperimen saja; $H_{1}: \mu_{1}>\mu_{2}=$ nilai rata-rata hasil belajar metode eksperimen menggunakan model PBL lebih besar atau sama dengan rata-rata hasil belajar menggunakan metode eksperimen saja.

Hasil penelitian ini didapatkan thitung 4,192 dan tabel 2,074. Oleh karena thitung $>$ tabel maka $\mathrm{H}_{1}$ diterima, yang berarti bahwa rata-rata hasil belajar siswa yang diterapkan metode eksperimen menggunakan model PBL lebih tinggi daripada hasil belajar siswa yang jika hanya diterapkan metode eksperimen saja.

\section{Pembahasan}

Penelitian ini dilakukan di MAN 1 Bitung semester genap tahun ajaran 2019/2020 pada Januari-Februari 2020 dengan menggunakan dua kelas untuk pengujian, yaitu kelas X MIA I sebagai kelas eksperimen dan kelas X MIA II sebagai kelas control. Berdasarkan jumlah siswa dikelas, untuk kelas eksperimen maupun kelas control masing-masing berjumlah 25 peserta didik.

Penelitian ini dilaksanakan dalam tiga kali pertemuan, pertemuan pertama diberikan materi pengantar larutan elektrolit dan non elektrolit sebagai responden, pertemuan kedua dilakukan kegiatan eksperimen dan pertemuan ketiga dilakukan pengambilan data pada kedua kelas tersebut yaitu dengan membetikan tes akhir (posttest) untuk pengukuran hasil belajar siswa tersebut. Untuk soal tes akhir tersebut 
sebelum digunakan sebagai instrument dalam penelitian untuk kedua sampel, semua butir soal yang digunakan telah telah divalidasi terlebih dahulu pada siswa yang sudah pernah diberi materi larutan elektrolit dan non elektrolit, yaitu pada kelas XII MIA di MAN 1 Bitung yang berjumlah 20 peserta didik.

Berdasarkan pengambilan data pada hasil penelitian yang dilaksanakn didapatkanbahwa pembelajaran menggunakan metode eksperimen menggunakan model PBL pada materi larutan elektrolit dan non elektrolit mampu menaikkan rata-rata nilai siswa. Hal tersebut dapat dilihat melalui hasil tes pada metode eksperimen dengan menggunakan model PBL lebih besar nilainya dibandingkan yang hanya mengguakan metode eksperimen saja. Perihal ini bisa dibuktikan melalui hasil ujihipotesis yang menggunakan uji $t$, yaitu hasil yang diperoleh untuk thitung $=4,192>$ tabel $=2,074$. Berdasarkan hasil penelitian maka metode eksperimen menggunakan model PBL pada materi larutan elektrolit dan non elektrolit dapat berpengaruh dalam meningkatkan ketuntasan rata-rata hasil belajar siswa dan dikung oleh penelitian sebelumnya [13]. Penyebabnya karena metode eksperimen menggunakan model PBL mampu membentuk fokus siswa dan bersemangat terhadap bahan ajar yang dipelajari karena pembelajaran tersebut dikaitkan dengan masalah yang terjadi setiap hari, yang menjadikan siswa lebih serius karena siswa mencoba sendiri mencari solusi dari masalah tersebut melalui pelaksanaan eksperimen hingga ilmu yang didapat lebih diingat dan dipahami dalam waktu panjang, sehingga dapat membuat peningkatan hasil belajar [14].

\section{Kesimpulan}

Berdasarkan penelitian yang sudahdilaksanakan serta data yang telah diperoleh, maka kesimpulannya terdapat pengaruh metode eksperimen menggunakan model PBL pada materi larutan elektrolit dan non elektrolit terhadap nilsi siswa di MAN 1 Bitung. penyebabnya karena pembelajaran dengan metode eksperimen menggunakan model PBL mampu menjadikan siswa lebih fokus dan bersemangat terhadap materi yang didapat karena pembelajaran tersebut dikaitkan dengan masalah yang terjadi di keseharian, yang membuat siswa lebih aktif lagi karena siswa bias mencari tahu sendiri solusi dari permasalahan itu melalui kegiatan eksperimen hingga pengetahuan yang mereka peroleh dapat lebih dipahami dan diingat dalam jangka waktu lama, sehingga dapat menaikkanhasil belajar siswa.

\section{Daftar Pustaka}

1. Penny, M.R.; Cao, Z.J.; Patel, B.; Santos, B.S. dos; Asquith, C.R.M.; Szulc, B.R.; Rao, Z.X.; Muwaffak, Z.; Malkinson, J.P.; Hilton, S.T. Three-Dimensional Printing of a Scalable Molecular Model and Orbital Kit for Organic Chemistry Teaching and Learning. Journal of Chemical Education 2017, 94, 1265-1271.

2. Pratt, J.M.; Yezierski, E.J. "You Lose Some Accuracy When You're Dumbing It Down": Teaching and Learning Ideas of College Students Teaching Chemistry through Outreach. J. Chem. Educ. 2019, 96, 203-212, doi:10.1021/acs.jchemed.8b00828.

3. Mongi, R.; Rampe, M.J.; Palilingan, S.C. Pengaruh Metode Problem Based Learning Pada Materi Redoks Di Kelas X SMA Negeri 1 Wori. Oxygenius Journal of Chemistry Education 2019, 1, 52-55.

4. Kousa, P.; Kavonius, R.; Aksela, M. LowAchieving Students' Attitudes towards Learning Chemistry and Chemistry Teaching Methods. Chemistry Education Research and Practice 2018, 19, 431-441, doi:10.1039/C7RP00226B.

5. Tahulending, A.W.; Rumampuk, R.; Aloanis, A.A. Pengembangan Penuntun Praktikum Reaksi Reduksi Dan Oksidasi Berbasis Bahan Alam Dengan Menggunakan Model ADDIE. Oxygenius Journal Of Chemistry Education 2019, 1, 6165.

6. Hubbi, M.; Dasna, I.W.; Wonorahardjo, S. Pengaruh Strategi Pembelajaran Praktikum Sifat Koligatif Terhadapa Hasil Belajar Siswa Kelas XII. EduChemia (Jurnal Kimia dan Pendidikan) 2017, 2, 52-62, doi:10.30870/educhemia.v2i1.1211.

7. Nanangkong, I.A.; Rumampuk, R.; Tani, D. Penerapan Penuntun Praktikum Dengan 
Menggunakan Metode Discovery Learning Untuk Meningkatkan Hasil Belajar Siswa Pada Materi Larutan Elektrolit Dan Nonelektrolit. Oxygenius Journal of Chemistry Education 2019, 1, 85-88.

8. Demo, D.N.; Waworuntu, F.; Saiya, A. Studi Kelayakan LKS Praktikum Berbasis Pendekatan Saintifik Serta Dampaknya Pada Hasil Belajar Materi Sifat Larutan Penyangga. Oxygenius Journal Of Chemistry Education 2019, 1, 77-84.

9. Gumolung, D.; Caroles, J. Studi Kelayakan Penuntun Praktikum Asam Basa Berbasis Bahan Lingkungan Menggunakan Model 3-D Dan Penerapan Metode Inkuiri Terbimbing Untuk Meningkatkan Hasil Belajar Siswa SMA Negeri 1 Tenga. Oxygenius Journal Of Chemistry Education 2019, 1, 40-47.

10. Vaino, K.; Holbrook, J.; Rannikmäe, M. Stimulating Students' Intrinsic Motivation for Learning Chemistry through the Use of Context-Based Learning Modules. Chemistry Education Research and Practice 2012, 13, 410-419, doi:10.1039/C2RP20045G.

11. Durant, C.; Pongoh, E.J.; Lumingkewas, S. Pengaruh model pembelajaran problem based learning terhadap hasil belajar siswa kelas X pada materi struktur atom di SMA katolik santa rosa de lima tondano. Oxygenius Journal Of Chemistry Education 2019, 1, 5-9.

12. Putri, T.K.; Waworuntu, F. Analisis Logam Timbal (Pb) Sebagai Pembelajaran Menggunakan Model Problem Based Learning Kabupaten Kepulauan Sangihe. Oxygenius Journal Of Chemistry Education 2020, 2, 10-15.

13. Günter, T.; Kılınç Alpat, S. The Effects of Problem-Based Learning (PBL) on the Academic Achievement of Students Studying 'Electrochemistry.' Chemistry Education Research and Practice 2017, 18, 7898, doi:10.1039/C6RP00176A.

14. Herawati, H.; Hakim, A.; Nurhadi, M. The Effectiveness of Inquiry-Based Learning with Multiple Representation to Improve Critical Thinking Skill in Learning Electrochemistry. In Proceedings of the AIP Conference Proceedings; American
Institute of Physics, April 1 2020; Vol. 2215, p. 020007.

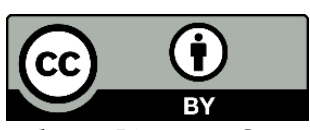

(C) 2020 by the authors. Licensee Oxygenius Journal Of Chemistry Education. This article is an open access article distributed under the terms and conditions of the Creative Commons Attribution (CC BY) license (http://creativecommons.org/licenses/by/4.0/). 